\title{
Presentado el estudio de viabilidad para la ampliación del Museo de Bellas Artes de Sevilla
}

En el contexto de la modernización emprendida por los museos a nivel nacional y europeo, de acuerdo con las últimas tendencias de la museología, y dado el impacto dinamizador de los servicios culturales de dicha institución en las ciudades, un equipo de técnicos del Centro de Intervención en el Patrimonio Histórico del IAPH aborda, a instancias de la Dirección General de Museos de la Consejería de Cultura de la Junta de Andalucía, la elaboración de un Estudio de Viabilidad sobre la posible Ampliación del Museo de Bellas Artes de Sevilla.

El documento nace de la necesidad de valorar las diversas posibilidades de crecimiento del Museo de Bellas Artes de Sevilla, analizadas desde dos perspectivas diferenciadas: las exigencias de adaptación a los criterios museológicos actuales; y la modernización de la institución, dotándola de un esquema funcional eficaz, de los sistemas tecnológicos necesarios para la presentación, conservación y seguridad de las colecciones, y de un programa de servicios al público propio de los museos del siglo XXI.

El diagnóstico general se basa en la constatación, a partir de la propuesta básica de ampliación elaborada por la dirección del museo, de las deficiencias programáticas de la actual sede, en lo referente a los requerimientos dimensionales y técnicos de las distintas áreas funcionales de la institución -área expositiva, área de conservación-restauración, área de gestión de colecciones, área didáctica, servicios al público, etc.-. Estas necesidades espaciales que se vienen manifestando desde la reforma integral del edificio del antiguo Convento de la Merced (1984-1993) tienen que abordarse para poder presentar una oferta competitiva en el campo de los museos, acorde con la demanda cultural de la ciudad, y capaz de dinamizar el tejido urbano en que se inserta.

Contrastadas las escasas posibilidades de una operación que retribuya en grandes espacios al antiguo Convento de la Merced -debido a la escasez de suelo libre en la colindancia del museo y a la frustración en las últimas décadas de varias posibilidades de ampliación, y con un nuevo programa de usos al que el edificio actual no puede dar respuesta, se plantea la obligatoriedad de realizar una operación de ampliación que palie estas necesidades y relance la imagen y servicios del centro.

El documento analiza, aportando consideraciones técnicas y patrimoniales, la viabilidad de las propuestas de ampliación barajadas por el
Museo de Bellas Artes y la Dirección General de Museos de la Consejería de Cultura de la Junta de Andalucia.

Las propuestas de crecimiento sobre el propio edificio -remontes en el edificio del Convento de la Merced, colmatación del Patio de las Conchas y construcción en la denominada "huerta" del Convento de la Merced- han sido desestimadas por su incapacidad para paliar definitivamente las demandas espaciales de la ampliación, y por su alto nivel de agresividad, no sólo con su imagen consolidada socialmente, sino con sus propias estructuras compositivas.

La propuesta de extensión por la trama urbana circundante mediante la incorporación de un inmueble próximo -operación cultural que cualificaría el tejido urbano en que se inserta con un uso público que compensa y complementa el carácter comercial del sector, y potencia nuevos recorridos turísticos-, también se descarta por el elevado coste económico de la adquisición de un inmueble de titularidad privada (Residencia Santa Ana) y por su insuficiencia espacial para solventar los requerimientos programáticos del museo.

Como resultado de este estudio, se defiende la idoneidad de ampliación del Museo de Bellas Artes con la incorporación del Palacio de Monsalves, edificio de fuerte entidad patrimonial y titularidad autonómica, ya que presenta una serie de ventajas que lo convierten en la última posibilidad viable de ampliación de la institución en el entorno próximo del Convento de la Merced.

A su favor operan factores de proximidad y cualidad urbana -que permiten la creación de una conexión peatonal entre ambas sedes-, su entidad patrimonial, ya que se puede musealizar como parte y contenido de la propia colección, la museología asumiría, por tanto, la conservación del inmueble y sus valores, como la colección de los fondos del Museo de Bellas Artes-, y su capacidad volumétrica y espacial de acoger al programa de usos propuestos sin menoscabo de sus valores patrimoniales.

Beatriz Castellano Bravo

José Luis Gómez Villa

Centro de Intervención del IAPH 